\title{
"Anti-lice Protector Shampoo": Clinical Study Shows Lack of Efficacy of Coconut Oil Derivatives in the Elimination of Head Louse Infestation
}

\author{
"Anti-lice Protector Shampoo": Klinik Çalışma, Hindistan Cevizi Yağı için \\ Etkinliğin Olmadiğını Gösteriyor
}

(1) Ian Faisal Burgess, (1) Nazma Akhter Burgess

Insect Research and Development Limited, Medical Entomology Centre, Cambridge, England

Cite this article as: Burgess IF, Burgess NA. "Anti-lice Protector Shampoo": Clinical Study Shows Lack of Efficacy of Coconut

Oil Derivatives in the Elimination of Head Louse Infestation. Turkiye Parazitol Derg 2020;44(4):211-5.

\begin{abstract}
Objective: Coconut oil and its derivatives are widely thought to kill head lice by occlusion and asphyxiation. There is no evidence in support of coconut derivative-based products sold to treat pediculosis. This study was designed to test one such product.

Methods: This was an open-label clinical study in 31 people. The treatment was shampoo containing $1 \%$ fractionated coconut oil. Treatment was given on day 0 and day 8 . Efficacy was measured using a detection comb on day 1, day 8 and day 16 after the first treatment. The trial was registered in the current controlled trials database, under number ISRCTN79136319.

Results: The first application of the product eliminated the lice from 7/31 participants, and 12/31 (38.7\%) people had no lice at the end of the study. Lice of all development stages were found post treatment at all assessments on one or more participants. This indicates that the treatment failed to kill all stages of the life cycle of head lice.

Conclusion: Two applications of the modified coconut shampoo were not effective at killing head lice or their eggs. The results confirm other studies that show little intrinsic activity in vegetable oils and modified oils. Most of the activity in shampoos is probably due to other product components, such as high levels of detergents.
\end{abstract}

Keywords: Head lice, coconut oil, shampoo, therapy

Öz

Amaç: Hindistan cevizi yağı ve türevlerinin, baş bitlerini tıkanma ve boğulma yoluyla öldürdüğü düşünülmektedir. Pediculosis tedavisi için satılan Hindistan cevizi türevi bazlı ürünlerin etkinliğini destekleyici bir kanıt yoktur. Bu çalışma, bu ürünlerden birini test etmek için tasarlanmıştır.

Yöntemler: Bu çalışma 31 kişi üzerinde yapılmıştır. Tedavide \%1 oranında parçalanmış Hindistan cevizi yağı içeren şampuan kullanılmıştır. Tedavi 0. ve 8. günlerde uygulanmıştır. Etkinlik, birinci tedaviden sonraki 1., 8. ve 16. günlerde bit tarağ 1 kullanılarak ölçülmüştür. Deneme, ISRCTN79136319 numaralı mevcut kontrollü denemeler veri tabanına kaydedilmiştir.

Bulgular: Ürünün ilk uygulamasıyla, 31 katılımcının yedisi bitlerden temizlenmiş ve çalışmanın sonunda ise 31 kişiden 12 'sinde $(\% 38,7)$ bit kalmamıştı. Tedavi sonrasında, bir veya daha fazla katılımcı üzerinde bitlerin tüm gelişme dönemlerine rastlanmıştır. Bu durum, uygulanan tedavinin baş bitlerini bütün gelişme dönemlerinde öldürmediğini göstermektedir.

Sonuç: Değiştirilmiş Hindistan cevizi şampuanının iki uygulaması, baş bitlerini veya yumurtalarını öldürmek için etkili olmamıştır. Bu sonuç, bitkisel yağlardan ve modifiye edilmiş yağlardan çok az intrinsik aktivite göstermiş diğer çalışmaları doğrulamaktadır. Şampuanların çoğunun aktiviteleri, muhtemelen yüksek oranda bulunan deterjan gibi diğer ürün bileşenlerinden kaynaklanmaktadir.

Anahtar Kelimeler: Saç biti, hindistan cevizi yağı, şampuan, terapi

\section{INTRODUCTION}

Numerous products are registered as medical devices in Europe for treatment or prevention of head louse infestation. All are sold with claims of efficacy. This marketing suggests there is supporting evidence for the claims, although most data have never been published. In practice, most products only have data from limited laboratory testing. There is also considerable variation

Received/Geliş Tarihi: 18.05.2020 Accepted/Kabul Tarihi: 17.07.2020

Address for Correspondence/Yazar Adresi: Ian Faisal Burgess, Insect Research and Development Limited, Medical Entomology Centre, Cambridge, England

Phone/Tel: +44 1223813696 E-mail/E-Posta: ian@insectresearch.com ORCID ID: orcid.org/0000-0003-0747-3938 
in the treatment regimens for these products despite never having been tested clinically. If there is no clinical evidence, it is likely that claims have been selected to make products appear more attractive to consumers.

A previous investigation evaluated the efficacy of a shampoo product claimed to be based on soya oil (1). It was subsequently discovered that the product tested did not contain any oil, and observed activity was attributed to the high concentration of surfactants in the product (2). This report describes a clinical investigation of a shampoo product originating from the same product development source. Most of the efficacy claims were essentially similar to those for the "soya" shampoo and this study was performed to determine whether the two products exhibited similar activity.

\section{METHODS}

\section{Study Design}

This was a single-centre, non-randomised, single-arm, openlabel study conducted in conformity with the principles of Good Clinical Practice and the Declaration of Helsinki. Ethical approval was granted by Cambridgeshire 1 Research Ethics Committee. reference 10/H0304/95. The trial was registered with the ISRCTN registry, number ISRCTN79136319 prior to commencement.

Recruitment of participants was by advertising in local news media. Respondents to the advertising were sent an information booklet describing the treatment and study procedures. When the study centre was contacted, after prospective participants had read the information, an appointment was made for a domiciliary visit by an investigator. All study procedures were performed during visits to participants at home using methods described previously $(1,3)$. The first stage of the recruitment process was for participants, or their parent/guardians to sign a consent form. Children younger than 16 years of age also provided written assent.

Participants were checked for an active head louse infestation by detection combing prior to treatment on day 0 . No count of lice or louse eggs was made at the time of enrolment but the level of infestation was described by how quickly lice were found during combing: heavy infestation $=>1$ louse with one stroke of the comb; moderate infestation $=1$ louse with one stroke of the comb; light infestation = first louse found only after several strokes of the comb. Participants confirmed they had had no nut related allergies, were not pregnant, and had not been treated with pediculicides for 2 weeks or with trimethoprim containing products for 4 weeks prior to entry.

\section{Treatment and Follow-up}

The test product, Anti-lice Protector (LHS Institut, St. Florian, Austria) consisting of $1 \%$ fractionated coconut oil in an aqueous shampoo basis, was provided in numbered bottles each containing $100 \mathrm{~mL}$ of shampoo. Each bottle was shaken thoroughly immediately before use because it was found to physically separate on standing. The product, applied to pre-wetted hair, was first used like an ordinary shampoo to clean the hair, rinsed, and partially towel dried. A greater quantity was then applied to the damp hair, sufficient that, when thoroughly massaged, it produced a homogeneous and stable foam that covered all the hair and scalp. If insufficient stable foam was built, more of the shampoo was applied, using more than one bottle if necessary. The foamed product was left in place for 15 minutes, after which the hair was rinsed with warm water. A second treatment was applied using the same methodology after the follow-up examination on day 8.

After treatment we assessed for persistent infestation using a plastic head louse detection comb (PDC, KSL Consulting, Helsinge, Denmark) during follow-up visits on day 1 , day 8 before application of the second treatment, and a final outcome check on day 16. On each occasion the whole hair and scalp was combed systematically and any lice recovered collected into the case record. At each treatment or follow-up examination any adverse experiences, whether or not due to the investigative product, were recorded.

\section{Statistical Analysis}

Analyses were planned for both the "intention-to-treat" and the "per-protocol" populations. For demographic characteristics the study group was compared with study groups from previous studies for comparability and generalizability of baseline characteristics, safety, acceptability and efficacy using Fisher's Exact test for yes/ no variables and the Mann-Whitney $U$ test for ranked variables. Analyses were performed using the online calculators available at https://www.socscistatistics.com/. If analysis showed important differences in baseline characteristics, chi-squared and rank tests stratified for these characteristics could also be conducted.

\section{RESULTS}

The study enrolled 31 participants from 18 families, with ages ranging from $2-43$ years (median 8 years), between $1^{\text {st }}$ April and $17^{\text {th }}$ June 2011. Of the participating families, 2,3 , or 6 members were represented by two households each; there were four households with 5 members, seven with 4 occupants, and one household with 9 members. Eleven of these households were represented by only one participant (Table 1 ). Twenty-four (77.4\%) participants were female. The age structure of this cohort was not significantly different from previous studies, with $19.4 \%$ participants aged between 2 and 5 years, $41.9 \%$ in the $6-9$ years age group, and $29 \%$ aged $10-15$ years. Three participants were over 16 , aged 37,38 , and 43 years (Table 2 ).

Other demographic characteristics such as hair length, thickness, degree of curl, and dryness/greasiness were similar to groups observed in previous studies. In this study the proportion of participants with infestations designated as heavy and moderate $(48.4 \%)$ was significantly $(\mathrm{p}<0.05)$ higher than found in some previous studies conducted in the same community (Table 2). However, in most cases, the actual intensity of infestation was probably greater than indicated by this semi-subjective measure. There was no identifiable relationship between intensity of infestation and hair length or thickness.

Follow up detection combing of participants was designed to not only measure the initial therapeutic impact of treatment but also to look for nymphs emerging from eggs not killed by the treatment. All participants had the presence of lice confirmed at day 0 and all had some viable eggs in their hair. All participants except one completed the study (Figure 1). The only withdrawal was participant 01 , on grounds of non-compliance, after the child's grandmother treated with $4 \%$ dimeticone lotion before the day 8 checkup and the second treatment. 


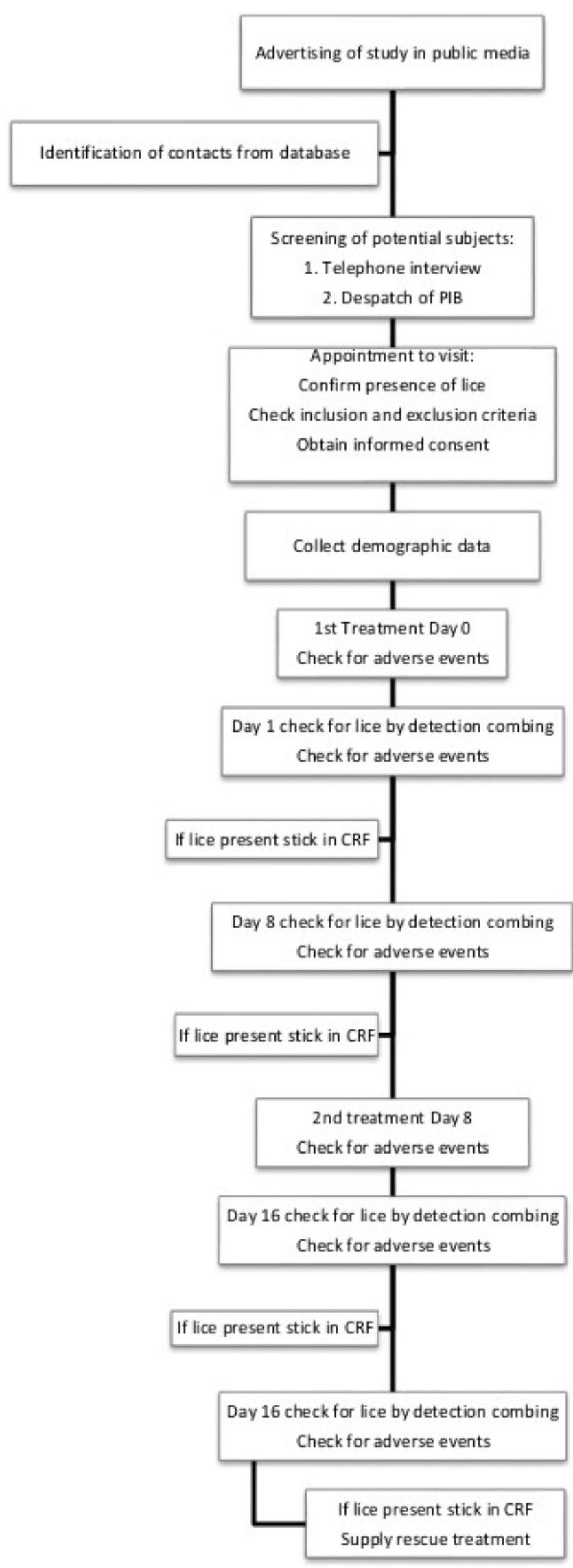

Figure 1. Flowchart of participants through the study
After the first treatment no lice were found on 10 participants, each from a different family. All others had lice present, ranging from one to 62 insects collected on day 1 . Lice from each life cycle stage were present on one or more individuals showing that, apart from a few nymphs that hatched since treatment, lice of all development stages were able to survive this treatment. A similar pattern was observed in the pre-treatment assessment on day 8 (Table 1). Following the second treatment, sufficient time elapsed for any surviving eggs to hatch before the final assessment on day 16. At this assessment $12 / 30$ (40\%) participants were found to be louse free, nine of whom had been louse free on day 1 . All other participants showed one or more lice at day 16 and were classified as treatment failures. Consequently, the rate of cure, the primary outcome variable, for the intention to treat group was $38.7 \%$ (12/31) and 41.3\% (12/29) for the per-protocol group (Figure 1). The cure rate following first treatment was $7 / 31$ (22.6\%). In general, the same pattern of infestation was observed throughout, with those people having larger numbers of lice on days 1 and 8 also showing larger numbers of lice on day 16 (Table 1 ).

All participants except 01 received two treatments using antilice protector shampoo. For 18 participants each treatment involved only one bottle. The others received two bottles for one or both treatments. Mean use for the first treatment was 78.9g (standard error $7.7 \mathrm{~g}$ ) with variation between $22.4 \mathrm{~g}$ and $155.9 \mathrm{~g}$. The weight of product used for the second treatment was similar in most cases, mean $77.8 \mathrm{~g}$ (standard error $8.6 \mathrm{~g}$ ) with a range from $8.9 \mathrm{~g}$ to $160.8 \mathrm{~g}$. There was no correlation between the quantity of shampoo used and the success rate for eliminating the infestation. Paradoxically, the mean quantity of shampoo used on those participants successfully treated $(135.5 \mathrm{~g})$ was about half that used on those whose treatment was not effective (263.0 g) and was likely more a reflection of the high proportion of males and older participants in the success group (Table 1).

\section{Adverse Events}

There were 17 reported adverse events related to treatment but no serious adverse events. Fifteen reported adverse events in nine people were variable levels of stinging, burning, or intense itching sensation of the scalp during the period that the treatment was in situ. All were recorded as "mild" in intensity except one which was recorded as "severe". In addition, one participant experienced a coughing fit possibly related to treatment during washing off the second shampoo treatment and another experienced dryness of the scalp for several days after completion of treatment.

\section{DISCUSSION}

This study has been to investigate the efficacy of a shampoo containing $1 \%$ fractionated coconut oil, which is most widely recognised as caprylic/capric triglyceride, a light and stable manufactured emollient that is miscible with oils or readily emulsifiable with surfactants. This material is a component of several head louse treatment shampoos that indicate "coconut oil" on the list of ingredients and claim to "suffocate" or "asphyxiate" the lice. However, evidence for efficacy of these shampoos is scant despite claims that they are "clinically tested" with no indication of whether or where any proper objective tests may have been conducted. One shampoo, listed as a coconut-derived emulsion, was tested in a school-based clinical study and obtained a success rate by intention to treat of $22 / 41(53.7 \%)$ at day 15 after two 
Table 1. Distribution of participants by household, infestation level, lice found per study day, and outcome of treatment

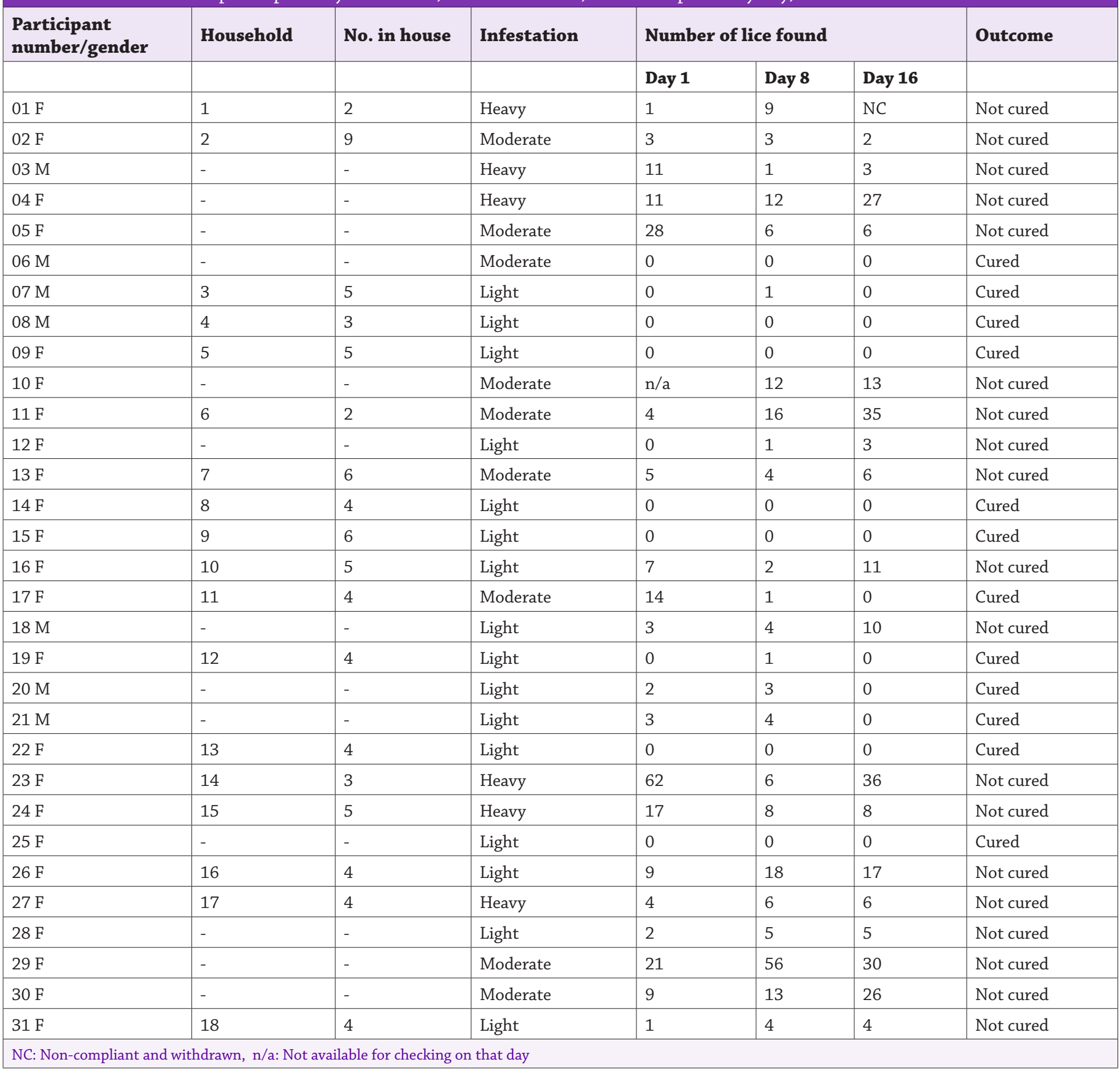

treatments one week apart (4), a result that was not significantly different from this study $(Z=-1.258, \mathrm{p}=0.20766)$.

A different type of product based on modified coconut oil, anise, and ylang-ylang with marketing claims that it had an asphyxiant effect derived most of its activity from the anise component (approximately $12 \%$ anethole) a well-recognised insecticide in other applications. Consequently, any claims for an occlusive action by the "coconut" component made by the manufacturer in relation to efficacy obtained in two studies comparing the product with insecticides $(5,6)$ were likely spurious and inaccurate. Even whole coconut oil (melting point $\sim 24^{\circ}$ Celsius) was shown ex vivo to have little activity until 4 hours had elapsed, eventually achieving 90\% louse kill (7). In contrast, olive oil, which is mainly made up of unsaturated fats with a similar carbon chain length to those of coconut oil, was found to kill only $2 \%$ of lice after 8 hours (8).

Irrespective of its chemical form, there is no evidence that small concentrations of either pure or modified fixed vegetable oils can have an effect on head lice, yet an internet search using the term "head lice vegetable oil" provided 1,830,00 responses, many of which were either advocating use of oils to kill lice or were advertising products containing oils. In the western world most people are unaware that coconut and similar oils have been regularly used over centuries as hair conditioning agents in much of Asia, Africa, and parts of the Americas, but the people using them can still have head lice. Based on the similarity between the 
Table 2. Demographic characteristics of participants and treatment success by characteristic

\begin{tabular}{|c|c|c|c|}
\hline \multicolumn{2}{|c|}{ Characteristic } & $\begin{array}{l}\text { Number } \\
\text { (percent) }\end{array}$ & $\begin{array}{l}\text { Treatment } \\
\text { success (percent) }\end{array}$ \\
\hline \multicolumn{2}{|c|}{ Number of participants } & 31 & $12(38.7 \%)$ \\
\hline \multirow{7}{*}{ Age } & $2-5$ & $6(19.4 \%)$ & $3(50.0 \%)$ \\
\hline & $6-9$ & $13(41.9 \%)$ & $3(23.1 \%)$ \\
\hline & $10-15$ & $9(29.0 \%)$ & $5(55.6 \%)$ \\
\hline & $>16$ & $3(9.7 \%)$ & $1(33.3 \%)$ \\
\hline & - & - & - \\
\hline & Median & 8 & - \\
\hline & - & - & - \\
\hline \multirow{3}{*}{ Gender } & Male & $7(22.6 \%)$ & $5(71.4 \%)$ \\
\hline & Female & $24(77.4 \%)$ & $7(29.2 \%)$ \\
\hline & - & - & - \\
\hline \multicolumn{4}{|c|}{ Previous treatment experience } \\
\hline \multicolumn{2}{|c|}{$\begin{array}{l}\text { Ever used head louse } \\
\text { treatment }\end{array}$} & $27(87.1 \%)$ & $8(29.6 \%)$ \\
\hline \multicolumn{2}{|c|}{$\begin{array}{l}\text { Previous treatment } \\
\text { successful }\end{array}$} & $10(32.3 \%)$ & $4(40.0 \%)$ \\
\hline \multicolumn{4}{|c|}{ Hair characteristics } \\
\hline \multirow{3}{*}{ Length } & Above ears & $7(22.6 \%)$ & $5(71.4 \%)$ \\
\hline & $\begin{array}{l}\text { Ears to } \\
\text { shoulders }\end{array}$ & $7(22.6 \%)$ & $2(28.6 \%)$ \\
\hline & $\begin{array}{l}\text { Below } \\
\text { shoulders }\end{array}$ & $17(54.8 \%)$ & $5(29.4 \%)$ \\
\hline \multirow{4}{*}{ Thickness } & Fine & $5(16.1 \%)$ & $3(60.0 \%)$ \\
\hline & Medium & $19(61.3 \%)$ & $5(26.3 \%)$ \\
\hline & Thick & $7(22.6 \%)$ & $4(57.1 \%)$ \\
\hline & - & - & - \\
\hline \multirow{3}{*}{ Curl } & Straight & $26(83.9 \%)$ & $8(30.8 \%)$ \\
\hline & Wavy/curly & $5(16.1 \%)$ & $4(80.0 \%)$ \\
\hline & - & - & - \\
\hline \multicolumn{4}{|c|}{ Infestation characteristics } \\
\hline & Light & $16(51.6 \%)$ & $10(62.5 \%)$ \\
\hline & Medium & $9(29.0 \%)$ & $2(22.2 \%)$ \\
\hline & Heavy & $6(19.4 \%)$ & $0(0.0 \%)$ \\
\hline
\end{tabular}

shampoo formulation used in this study and that tested previously under the guise of a soya-based shampoo, it is likely that what efficacy was observed in this study was due to the high surfactant levels in the product rather than any effect of the caprylic/capric triglyceride.

\section{CONCLUSION}

This study has shown that a modified coconut oil shampoo has a limited effect to adequately treat head louse infestation with only $41.3 \%$ success in the per-protocol population. This result supports other reported outcomes using similar preparations in which vegetable oils and their derivatives showed little efficacy beyond that which could be imputed to the formulation excipients, such as surfactants included at relatively high concentrations.

\section{ACKNOWLEDGEMENT}

Dr Paul Silverston provided medical supervision for clinical queries. Elizabeth Brunton and Ben Hall performed some post treatment assessments.

\section{* Ethics}

Ethics Committee Approval: Ethical approval was granted by Cambridgeshire 1 Research Ethic Committee reference 10/ H0304/95.

Informed Consent: Written consent was obtained.

Peer-review: Internally peer-reviewed.

\section{* Authorship Contributions}

Concept: I.F.B., Design: I.F.B., N.A.B., Data Collection or Processing: I.F.B., N.A.B., Analysis or Interpretation: I.F.B., Literature Search: I.F.B., Writing: I.F.B.

Conflict of Interest: No conflict of interest was declared by the authors.

Financial Disclosure: The clinical study was commercially funded and clinical supplies provided by LHS Institut, St Florian, Austria and Fulltec AG, Zug, Switzerland. The decision to publish was that of the authors and no funding was received for this work.

\section{REFERENCES}

1. Burgess IF, Kay K, Burgess NA, Brunton ER. Soya oil based shampoo superior to $0.5 \%$ permethrin lotion against head louse infestation. Med Devices (Auckl) 2011; 4: 35-42.

2. Burgess IF. Soya oil based shampoo superior to $0.5 \%$ permethrin lotion against head louse infestation [Corrigendum]. Med Devices (Auckl) 2015; 8: 295-6.

3. Burgess IF, Lee PN, Matlock G. Randomised, controlled, assessor blind trial comparing $4 \%$ dimeticone lotion with $0.5 \%$ malathion liquid for head louse infestation. PLoS ONE 2007; 2: e1127.

4. Connolly M, Stafford KA, Coles GC, Kennedy CTC, Downs AMR. Control of head lice with a coconut-derived emulsion shampoo. J Eur Acad Dermatol Venereol 2009; 23: 67-9.

5. Mumcuoglu KY, Miller J, Zamir C, Zentner G, Helbin V, Ingber A. The in vivo pediculicidal efficacy of a natural remedy. Isr Med Assoc J 2002; 4: 790-3.

6. Burgess IF, Brunton ER, Burgess NA. Clinical trial showing superiority of a coconut and anise spray over permethrin $0.43 \%$ lotion for head louse infestation, ISRCTN96469780. Eur J Pediatr 2010; 69: 55-62.

7. Asenov A, Oliveira FA, Speare R, Liesenfeld O, Hengge UR, Heukelbach J. Efficacy of chemical and botanical over-the-counter pediculicides available in Brazil, and off-label treatments, against head lice ex vivo. Int J Dermatol 2010; 49: 324-30.

8. Takano-Lee M, Edman JD, Mullens BA, Clark JM. Home remedies to control head lice: assessment of home remedies to control the human head louse, Pediculus humanus capitis (Anoplura: Pediculidae). J Pediatr Nurs 2004; 19: 393-8. 